\title{
Design and Implementation of Human Resource Information Management System
}

\author{
Mengqing Jia ${ }^{a}$, Yanli Chang ${ }^{b}$, Yanping Chen, Liruo Lu \\ State Grid Henan Electric Power Company Luoyang Power Supply Company, Luoyang 471000, \\ China \\ a284307335@qq.com, b1015903240@qq.com
}

Keywords: Human resource, Information management, architecture.

\begin{abstract}
Under the conditions of market economy, competition among enterprises is the talent competition, the traditional human resource management in the macroeconomic environment in the information age, companies cannot meet in tissue culture, technological innovation and access to, maintain, motivate, evaluate personnel and other requirements. Human Resource Management Information System (Human Resource MIS, referred to as HRMS) came into being on the basis of the use and the development of human resource management theory of new technologies over.
\end{abstract}

\section{Introduction}

Information technology to promote the national economy mainly in management, scientific computing and production control and other aspects of the strong application of information technology, among the most prominent management, probably accounted for at this stage, or more. Management of information technology has developed into a special "management information system." Since our country to promote micro-computer applications since, in the "Management Information System" in the field, both in theory or have a lot of development in practice.

The greatest feature of the management information system is highly concentrated, can organize the data and information together, fast processing, unified use. There is a central database and computer network system is an important symbol. MIS, a distributed processing approach is based on the database and network. With the development of computer networks and communication technologies at all levels of the organization can not only manage internal link up, and be able to overcome geographical boundaries, scattered in different parts of the computer network interconnection, the formation of a variety of business information systems and management information across regions system.

\section{Situation of Human Resource Management System}

The company's human resources work is divided into six main parts, namely, organization building, post system, training system, performance management, compensation management and career development. With the progress and the complexity of the company's human resources management standards, existing human resources management information system cannot meet the needs of everyday human resource management: management functions such as labor contract cannot be process control, the probation period and contract period does not automatically calculations, the contract expires without warning function; custom features work reports inflexible; lack of employee self-service platform and decision analysis. The company hopes to replace the existing system, and the existing work in maintaining the existing working mechanism without changing innovation.

Organizational management company is defined according to business development organization needs and practical work requirements, at all levels throughout the company, to manage the preparation, provide clear responsibilities, reasonable division of labor organizations ensure streamlined and efficient for the whole company's business operation. Company organization management business, including the organization category management, organization design and management, organization and staffing management and organization code management. 


\section{The Problem about Development of Human Resources Information Management System}

First, the system must be planned. This includes making all staff fully understand the concept of human resource information system design considerations and program personnel information processing systems development schedule make arrangements to establish accountability and the various rules and regulations and so on.

Secondly, it is about the design and development of the system. Including analysis of existing records, reports and forms to determine the data requirements of human resources information system to determine the final content of the database structure documentation and coding for generating and updating data preservation and calculation procedures specified personnel reporting requirements and formats determine the structure, form and content of the human resources information system technology to determine the format and content of the files on your computer, such as employee wages and benefits tables required to determine wages and other system interface requirements and human resource information systems.

Thirdly, it is the system implementation. Including a study of current and future use of the system in order to identify potential environmental problems check your computer hardware architecture, software constraints affect the language and system design to determine the input - output conditions require, run times and provide information about the actual processing amount of processing capacity, the operator request process, data users and facilities required educational background design data input files, transaction processing procedures and human resources information system input.

Finally, it is the evaluation system. Including the estimated cost to improve personnel management to identify key management personnel of the information required to determine what special people to add specific information requirements of the organizational issues related to human resources information system proposals put forward proposals to ensure the security of confidential information.

\section{System Function}

Use of this system can be part of the process of using computer processing office automation, efficiency and accuracy can be greatly improved office. In addition, you can easily analyze statistics and information required to facilitate the adjustment of the respective policies. The system is a web-based information management system, network processing functions. The system uses an advanced system architecture and application development model; improve system scalability, maintainability, and interactivity. The system is relatively independent of the interface is simple, safe, easy to operate.

The company's human resources information management system using Web-based B / S structure of the development, centralized management of data, enabling a high degree of sharing of information; regardless of the complexity of the organization, how decentralized offices, the browser can provide accurate, real-time and valid data to support the Group centralized / decentralized management, cross-industry, cross-regional group of management, mobile office, instant control of information to help companies respond quickly to market.

(1) Organizational structure

This module from the business process, analyzing the work plan and set up the organization at all levels and positions, determine the preparation, clear job responsibilities and capabilities of the relevant personnel, provide job management tools to support business development strategy. Through the organization management, management systems, sector analysis, job analysis, job analysis, Administrative Templates, Report Center and other functional modules to achieve a series of management and organizational analysis, to achieve the company's organizational set up, job analysis and job settings, organizational management and generate reports.

(2) Recruitment Management

System through the Internet / Intranet to complete the whole process of screening and interviewing scores of people from requirements analysis to job, hiring staff and personnel data directly into the 
archives, and internal recruitment, through the intranet, employees can see the vacancies promptly released; you can apply online for the position. Plans to recruit from a job, job information, and gathering candidates resume job qualifications by the selection, management interview results to inform the management of the whole process of the trial.

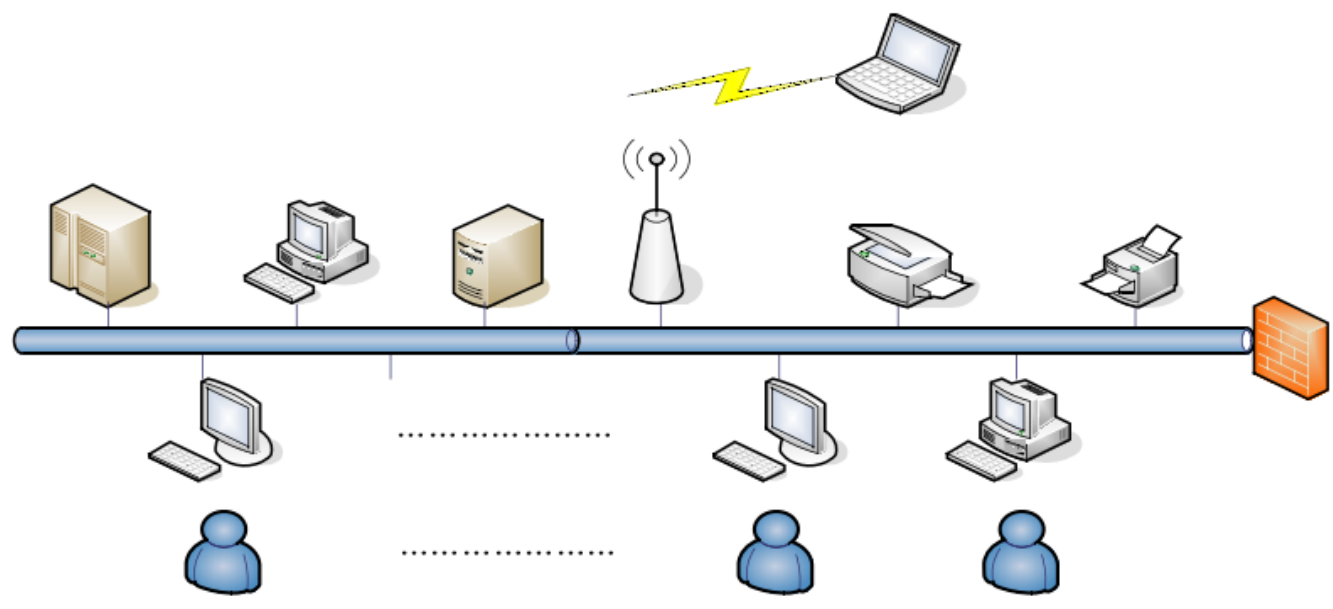

Figure1: The Architecture of Human Resource Information Management System

(3) Employee Information Management

This module is the basic data module system, with daily transaction processing functions of human resource management and provide real-time, efficient data access, information management features are available to all employees via Internet / Intranet implementation, which includes files, history, staff change and management positions. Can be very convenient for staff query statistics, and export a variety of standard reports. By hires, employee basic information, employee assistance information, positive management, contract management, personnel change management, leave management, reward management, penalties, Management Templates, Report Center and other functional modules to achieve a number of personnel on the management process, to facilitate record and analysis of the human resource situation in the various stages of the enterprise at all levels of employees into the company from the beginning till the departure of the entire process of comprehensive management, and various changes in employee files saved as a history record check, personnel management reports can be generated.

(4) Attendance

Pour the attendance of staff attendance officers, and employees on the Internet to check their records for the error information feedback, online access and supervisor approval, retroactive data confirmed automatically after vacation, wages module. Systems based on the actual situation on the non-normal work of the staff records and statistics, such as scheduling and other management, payroll calculation, labor cost allocation and performance evaluation to provide accurate definition based on flexible working hours set the type of shift work and overtime; individual / department / company's attendance data for statistical analysis and comparison with the chart.

(5) The remuneration and benefits

Compensation Management module involves remuneration standards (sets of accounts) settings, initialization, calculate attendance-related, insurance, bonuses, among other factors. System to co-ordinate various social insurance and personal income tax calculation and management need to be set up in accordance with national and regional requirements, the withholding income tax returns can be submitted directly to the tax authorities, employees can check their pay and benefits this month, details, details the history of compensation and benefits. System covers a variety of cash and non-cash compensation management, formulas and organizational positions, personal ability, attendance, performance and training outcomes related to accounting, statistics, payment and other 
transactional work done in a unified platform, each sub-group the company also can handle alone business, define their own processes, produce different types of reports.

\section{Summary}

This paper made a more in-depth and comprehensive study on the analysis and design of human resource management information system in the process of testing and trial phase of the system is completed, the system is able to complete successfully the personnel records management, compensation management, recruitment management, career planning resource information management, user settings, and all data required for the management of human resources functions, various aspects have to achieve the desired objectives. By using this system, greatly improving the level of human resource management and efficiency, giving business managers bring great convenience, but also greatly reduces the workload of human resource management, saving time and increasing the quality of service and cost, get a good evaluation.

\section{Reference}

[1] Chen, Peng Cui human resource management information and effective measures to implement the conditions [J] National Offers (economic theory), 2008,01: 44-46.

[2] Liu Yu, Mei-yun, Chen Yu indicators of human resources information maturity model design [J] Technology Progress and Policy, 2008,04: 186-189.

[3] Liu Xin large conglomerates human resource management, information technology [J] the power of information technology, 2011,05: 47-50.

[4] Konglin Jun, Modern enterprise human resources information management [J] business culture (first half), 2011,10: 48-49.

[5] Tian Xu. ERP and enterprise human resources information technology [J] Issues Information Development \& Economy, 2006,07: 229-230. 